Proceedings

\title{
Heterogeneous Catalytic Ozonation of Micropollutants in a Pilot Scale Continuous Flow System ${ }^{+}$
}

\author{
Efthimia Kaprara ${ }^{1}$, Chrysovalantou Koutsiantzi ${ }^{1}$, Savvina Psaltou ${ }^{2}$, Anastasios Zouboulis ${ }^{2}$ and \\ Manassis Mitrakas 1,* \\ 1 Division of Analytical Chemistry, Department of Chemical Engineering, Aristotle University, \\ 54124 Thessaloniki, Greece; kaprara@auth.gr (E.K.); koutsiac@cheng.auth.gr (C.K.) \\ 2 Division of Chemical and Environmental Technology, Department of Chemistry, Aristotle University, \\ 54124 Thessaloniki, Greece; spsaltou@chem.auth.gr (S.P.); zoubouli@chem.auth.gr (A.Z.) \\ * Correspondence: manasis@eng.auth.gr \\ + Presented at the 4th EWaS International Conference: Valuing the Water, Carbon, Ecological Footprints of \\ Human Activities, Online, 24-27 June 2020.
}

Published: 13 August 2020

\begin{abstract}
The present study evaluates micropollutant degradation from water by catalytic ozonation in a pilot scale unit comprising of a hydrophobic membrane for ozone dilution and a column filled with granules of the catalyst. The catalysts examined are alumina, calcite, dolomite, goethite, pearlite, polyethylene terephthalate (PET) and zeolite. Experimental results revealed zeolite as the most effective material achieving complete degradation of benzotriazole and carbamazepine, as well as $70 \%$ degradation of atrazine and about $50 \%$ of p-chlorobenzoic acid (pCBA). The rest of the catalysts tested presented a moderate performance in micropollutant removal, reaching $30 \%-50 \%$ for atrazine, $25 \%-35 \%$ for $\mathrm{p}-\mathrm{CBA}$, more than $90 \%$ for benzotriazole and complete degradation of carbamazepine. Adsorption capacity of all materials examined did not exceed $5 \%$.
\end{abstract}

Keywords: heterogeneous catalytic ozonation; micropollutants; water treatment; continuous flow

\section{Introduction}

The increasing worldwide consumption of chemical products has led to increasing chemical pollution of aquatic environments including sewage, surface water, groundwater and drinking water $[1,2]$. These chemical products comprise pharmaceuticals, personal care products, steroid hormones and plasticizers that are usually termed as micropollutants, due to their low concentrations ( $\mathrm{pg} / \mathrm{L}$ to $\mathrm{ng} / \mathrm{L}$ ) in aquatic ecosystems [3]. A major pathway for the introduction of micropollutants to surface water is the discharge of treated effluent from wastewater treatment plants (WWTPs). Given their diverse properties (e.g., hydrophobicity and biodegradability) and low concentrations, micropollutant removal in conventional WWTPs is commonly incomplete and variable, ranging from $12.5 \%$ to $100 \%$ for some frequently reported compounds [1].

Micropollutants removal is dependent on compound - and process - specific factors. Biological treatment is commonly unable to remove polar persistent micropollutants [1]. Advanced treatment processes, such as activated carbon adsorption [4], advanced oxidation processes, nanofiltration (NF) [5], reverse osmosis (RO) [6] and membrane bioreactors (MBRs) [7] can achieve higher and more consistent micropollutant removal. However, activated carbon effectiveness is strongly affected by the presence of natural organic matter competing for adsorption sites, hence resulting in blocked pores [1]. NF and $\mathrm{RO}$, although widely used in water reuse industry due to their high pollutant removal efficiency, are permeable to some degree to certain relatively small micropollutants [8]. On 
the other hand, MBRs can effectively remove a wide spectrum of micropollutants including compounds that are resistant to activate sludge processes [7]. Nevertheless, the removal of micropollutants in MBR can be affected by several factors, such as sludge age and concentration, existence of anoxic and anaerobic compartments, composition of the wastewater, operating temperatures, $\mathrm{pH}$ and conductivity [9].

Ozonation and advanced oxidation processes (AOPs) are effective redox technologies that prevail over conventional treatments, due to their high degradation rates and non-selectivity. However, high ozonation efficiency may also present undesirable side effects, such as specific byproduct formation, which can be as harmful as the original pollutants that were treated [10]. In order to further reduce parent compounds and oxidation by-products, the ozonation process can be optimized through the presence of an appropriate catalyst (catalytic ozonation) [11]. Catalytic ozonation can be divided into homogeneous (transition metal ions) and heterogeneous catalytic ozonation (solid materials). Catalytic ozonation is based on the degradation of organic compounds via the decomposition of $\mathrm{O}_{3}$ into hydroxyl radicals $(\cdot \mathrm{OH})$, that are a powerful and non-selective oxidant [11]. Micropollutants in the ozonation processes can be categorized based on the reaction rate constant with $\mathrm{O}_{3}$ into three groups: $\mathrm{O}_{3}$-resistant compounds, moderately $\mathrm{O}_{3}$ reactive compounds and high/moderate $\mathrm{O}_{3}$ reactive compounds [12].

The aim of this study is to examine the potential of several materials to act as catalysts to the ozonation of micropollutants by evaluating the removal of low concentration $(2 \mu \mathrm{M})$ micropollutants that belong to these three categories. For that purpose, four different compounds were used: atrazine (ATZ) (O3-resistant compound) [13], benzotriazole (BTA) (moderately O3-reactive compound) [14], carbamazepine (CBZ) (easy-reactive compound) [15] and p-chlorobenzoic acid (p-CBA) (O-resistant compound) [16]. The materials examined as catalysts are alumina, calcite, dolomite, goethite, pearlite, PET and zeolite, while all experiments were performed in a pilot scale unit operating in continuous mode in order to simulate real process conditions.

\section{Materials and Methods}

\subsection{Materials and Reagents}

All chemicals were of analytical grade, except for HPLC-grade acetonitrile (Chem-lab, Zedelgem, Belgium) and phosphoric acid (Sigma-Aldrich, St. Louis, MO, USA). Atrazine, benzotriazole, carbamazepine and p-CBA (Sigma-Aldrich, St. Louis, MO, USA) were used as model organic compounds. The materials examined as catalysts were alumina, calcite, dolomite, goethite, pearlite, PET and zeolite. Experiments' solutions were prepared in Thessaloniki's tap water while target $\mathrm{pH}$ values were adjusted by the addition of either $\mathrm{HNO}_{3}$ or $\mathrm{NaOH} 1 \mathrm{~N}$.

\subsection{Analytical Methods}

The initial and residual concentration of the micropollutants was determined by using the HighPerformance Liquid Chromatography system (HPLC Thermo Fisher Scientific Inc., model of UV Spectrum UV2000, Waltham, MA, USA) at $254 \mathrm{~nm}$, equipped with a $4.6 \mathrm{~mm} 250 \mathrm{~mm}$ reversed phase column (AGILENT, model Eclipse Plus C18, Santa Clara, CA, USA). The mobile phase consisted of $10 \mathrm{mM}$ phosphoric acid and acetonitrile in the percentages shown in Table 1. The detection limit of the micropollutants was $0.025 \mu \mathrm{M}$. The $\mathrm{O}_{3}$ concentrations in aqueous solutions were determined by using the indigo method [17]. The color change of the indigo solution was determined by a U-5100 Hitachi spectrophotometer. 
Table 1. Mobile phase proportion for micropollutants detection by HPLC.

\begin{tabular}{ccc}
\hline Micropollutant (MP) & $\mathbf{1 0} \mathbf{~ m M ~ H}_{3} \mathbf{P O}_{4}, \%$ v/v & $\mathbf{A C N}_{\mathbf{\gamma}} \% \mathbf{v} / \boldsymbol{v}$ \\
\hline Atrazine & 5 & 50 \\
Benzotriazole & 75 & 25 \\
Carbamazepine & 60 & 40 \\
p-CBA & 60 & 40 \\
\hline
\end{tabular}

Surface area and pore size distribution of materials tested as catalysts were estimated by nitrogen gas adsorption at liquid $\mathrm{N}_{2}$ temperature $(77 \mathrm{~K})$ using a micropore surface area analyzer according to the Brunauer-Emmett-Teller (BET) model. The electric surface properties were examined through the measurement of the isoelectric point (IEP) which describes the effective charge at the surface double layer and the point of zero charge (PZC), which indicates the actual charge at the catalysts' surface. Particularly, IEP was determined by the curve of zeta-potential at $20 \pm 1{ }^{\circ} \mathrm{C}$ of materials' dispersion in $0.01 \mathrm{M} \mathrm{NaNO}_{3}$ versus $\mathrm{pH}$ solution, using a Rank Brothers Microelectrophoresis Apparatus Mk II device, while PZC was defined by acid/base potentiometric mass titration in suspensions of the adsorbent at various ionic strengths [18].

\subsection{Experimental Set-Up}

Experiments of catalytic ozonation were performed in a pilot scale unit comprising of a hydrophobic membrane and a column filled with granules of the catalyst (Figure 1). The membrane, PDMSXA-2500 (purchased from PermSelect) offered the adequate contact surface for ozone dilution to water. The initial concentration of micropollutants was set to $2 \mu \mathrm{M}$, the $\mathrm{pH}$ ranged from 6 to 8 and contact time from 2 to $15 \mathrm{~min}$, while pilot unit provided an ozone concentration of $2 \mathrm{mg} \mathrm{O} / \mathrm{L}$. The affinity/adsorption of micropollutants against the applied catalysts was evaluated through their adsorption capacity.

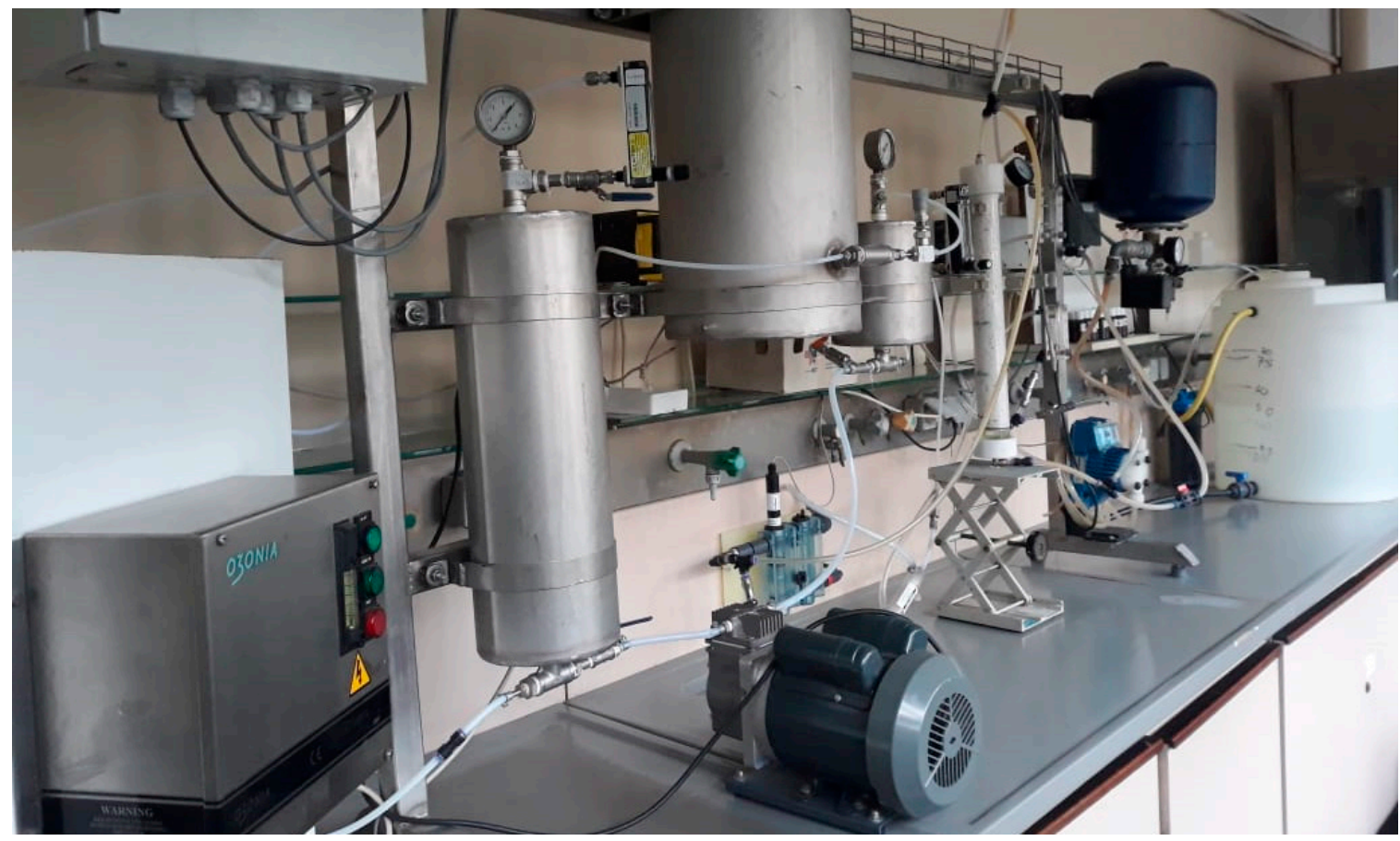

Figure 1. Catalytic ozonation continuous flow pilot unit. 


\section{Results}

\subsection{Physicochemical Properties of Materials Tested as Catalysts}

Table 2 summarizes the main physicochemical characteristics of materials tested as catalysts as determined by the methods described at Section 2.2. As shown, PZC values for all catalysts were close or higher than 7 which also stands for IEP with the exception of zeolite for which an IEP value of 2.2 was determined. The specific surface area of materials varied from $6.3 \mathrm{~m}^{2} / \mathrm{g}$ for calcite to 150 for alumina which also presented the highest pore volume followed by goethite and zeolite.

Table 2. Main physicochemical characteristics of materials tested as catalysts

\begin{tabular}{ccccc}
\hline Catalyst & PZC & IEP & S $_{\text {вET, }}\left(\mathbf{m}^{2} / \mathbf{g}\right)$ & Pore volume $(\mathbf{m L} / \mathbf{g})$ \\
\hline Alumina & 8.5 & 7.5 & 150 & 0.512 \\
Calcite & 9.7 & 8.2 & 6.3 & 0.038 \\
Dolomite & 10.1 & 9.3 & 5.1 & 0.030 \\
Goethite & 7.8 & 7.4 & 135 & 0.265 \\
Pearlite & $/$ & $/$ & 1.92 & 0.035 \\
PET & 6.2 & $/$ & $/$ & $/$ \\
Zeolite & 6.8 & 2.2 & 21 & 0.164 \\
\hline
\end{tabular}

\subsection{Continuous Flow Experiments}

Catalytic ozonation experiments were performed in the continuous flow pilot unit described at Section 2.3. Samples for analysis were collected after the membrane and at the outflow of catalytic ozonation. Part of the sample collected after the membrane was placed in a sealed beaker where ozonation reaction continued for a period of time equal to the catalytic ozonation contact time. Residual concentrations of ozone and micropollutant were measured to all samples. The results of continuous flow experiments with regard to tested materials performance in catalytic ozonation are presented in Tables 3-9.

Table 3. Micropollutant removal and ozone decomposition in catalytic ozonation with alumina ( $\mathrm{C}_{0, \text { eozon: }} 2 \mathrm{mg} / \mathrm{L}, \mathrm{C}_{0}$, MP: $2 \mu \mathrm{M}, \mathrm{pH}: 7$, contact time: $7 \mathrm{~min}$ ).

\begin{tabular}{|c|c|c|}
\hline \multicolumn{3}{|c|}{ ALUMINA } \\
\hline \multicolumn{3}{|c|}{ Micropollutant Removal, \% } \\
\hline Micropollutant & Adsorption & Catalytic ozonation \\
\hline $\mathrm{p}-\mathrm{CBA}$ & $<2 \%$ & $29 \%$ \\
\hline ATZ & $5 \%$ & $43 \%$ \\
\hline BTA & $5 \%$ & $95 \%$ \\
\hline CBZ & $<2 \%$ & $>99 \%$ \\
\hline \multicolumn{3}{|c|}{ Ozone decomposition in catalytic ozonation, $\%$. } \\
\hline p-CBA & ATZ $\quad$ BTA & CBZ \\
\hline$>99 \%$ & $>99 \% \quad>99 \%$ & $>99 \%$ \\
\hline
\end{tabular}


Table 4. Micropollutant removal and ozone decomposition in catalytic ozonation with calcite ( $\mathrm{C}_{0}$, ozone: $2 \mathrm{mg} / \mathrm{L}, \mathrm{C}_{0}$, MP: $2 \mu \mathrm{M}, \mathrm{pH}: 7$, contact time: $7 \mathrm{~min}$ ).

\begin{tabular}{|c|c|c|}
\hline \multicolumn{3}{|c|}{ CALCITE } \\
\hline \multicolumn{3}{|c|}{ Micropollutant Removal, \% } \\
\hline Micropollutant & Adsorption & Catalytic ozonation \\
\hline $\mathrm{p}-\mathrm{CBA}$ & $5 \%$ & $30 \%$ \\
\hline ATZ & $<2 \%$ & $42 \%$ \\
\hline BTA & $5 \%$ & $92 \%$ \\
\hline CBZ & $<2 \%$ & $>99 \%$ \\
\hline \multicolumn{3}{|c|}{ Ozone decomposition in catalytic ozonation, $\%$} \\
\hline p-CBA & ATZ BTA & CBZ \\
\hline $90 \%$ & $83 \%$ & $>99 \%$ \\
\hline
\end{tabular}

Table 5. Micropollutant removal and ozone decomposition in catalytic ozonation with dolomite ( $\mathrm{C}_{0, \text { ozone: }} 2 \mathrm{mg} / \mathrm{L}, \mathrm{C}_{0}$, MP: $2 \mu \mathrm{M}, \mathrm{pH}: 7$, contact time: $7 \mathrm{~min}$ ).

\begin{tabular}{|c|c|c|}
\hline \multicolumn{3}{|c|}{ DOLOMITE } \\
\hline \multicolumn{3}{|c|}{ Micropollutant Removal, \% } \\
\hline Micropollutant & Adsorption & Catalytic ozonation \\
\hline $\mathrm{p}-\mathrm{CBA}$ & $5 \%$ & $31 \%$ \\
\hline ATZ & $<2 \%$ & $43 \%$ \\
\hline BTA & $5 \%$ & $90 \%$ \\
\hline CBZ & $<2 \%$ & $>99 \%$ \\
\hline \multicolumn{3}{|c|}{ Ozone decomposition in catalytic ozonation, $\%$} \\
\hline $\mathrm{p}-\mathrm{CBA}$ & ATZ BTA & $\mathrm{CBZ}$ \\
\hline $89 \%$ & $77 \% \quad 85 \%$ & $>99 \%$ \\
\hline
\end{tabular}

Table 6. Micropollutant removal and ozone decomposition in catalytic ozonation with goethite ( $\mathrm{C}_{0}$, ozone: $2 \mathrm{mg} / \mathrm{L}, \mathrm{C}_{0}, \mathrm{MP}: 2 \mu \mathrm{M}, \mathrm{pH}: 7$, contact time: $7 \mathrm{~min}$ ).

\begin{tabular}{|c|c|c|}
\hline \multicolumn{3}{|c|}{ GOETHITE } \\
\hline \multicolumn{3}{|c|}{ Micropollutant Removal, \% } \\
\hline Micropollutant & Adsorption & Catalytic ozonation \\
\hline $\mathrm{p}-\mathrm{CBA}$ & $<2 \%$ & $25 \%$ \\
\hline ATZ & $<2 \%$ & $31 \%$ \\
\hline BTA & $<2 \%$ & $>99 \%$ \\
\hline $\mathrm{CBZ}$ & $<2 \%$ & $>99 \%$ \\
\hline \multicolumn{3}{|c|}{ Ozone decomposition in catalytic ozonation, $\%$} \\
\hline $\mathrm{p}-\mathrm{CBA}$ & ATZ & CBZ \\
\hline$>99 \%$ & $>99 \%$ & $>99 \%$ \\
\hline
\end{tabular}


Table 7. Micropollutant removal and ozone decomposition in catalytic ozonation with pearlite ( $\mathrm{C}_{0}$, ozone: $2 \mathrm{mg} / \mathrm{L}, \mathrm{C}_{0}$, MP: $2 \mu \mathrm{M}, \mathrm{pH}: 7$, contact time: $7 \mathrm{~min}$ ).

\begin{tabular}{|c|c|c|}
\hline \multicolumn{3}{|c|}{ PEARLITE } \\
\hline \multicolumn{3}{|c|}{ Micropollutant Removal, \% } \\
\hline Micropollutant & Adsorption & Catalytic ozonation \\
\hline $\mathrm{p}-\mathrm{CBA}$ & $3 \%$ & $31 \%$ \\
\hline ATZ & $5 \%$ & $28 \%$ \\
\hline BTA & $5 \%$ & $98 \%$ \\
\hline CBZ & $<2 \%$ & $>99 \%$ \\
\hline \multicolumn{3}{|c|}{ Ozone decomposition in catalytic ozonation, $\%$} \\
\hline $\mathrm{p}-\mathrm{CBA}$ & ATZ BTA & CBZ \\
\hline $70 \%$ & $76 \%$ & $>99 \%$ \\
\hline
\end{tabular}

Table 8. Micropollutant removal and ozone decomposition in catalytic ozonation with PET ( $\mathrm{C}_{0}$, ozone: $2 \mathrm{mg} / \mathrm{L}, \mathrm{C}_{0}, \mathrm{MP}: 2 \mu \mathrm{M}, \mathrm{pH}: 7$, contact time: $7 \mathrm{~min}$ ).

\begin{tabular}{|c|c|c|}
\hline \multicolumn{3}{|c|}{ PET } \\
\hline \multicolumn{3}{|c|}{ Micropollutant Removal, \% } \\
\hline Micropollutant & Adsorption & Catalytic ozonation \\
\hline $\mathrm{p}-\mathrm{CBA}$ & $5 \%$ & $35 \%$ \\
\hline ATZ & $<2 \%$ & $53 \%$ \\
\hline BTA & $<2 \%$ & $>99 \%$ \\
\hline CBZ & $<2 \%$ & $>99 \%$ \\
\hline \multicolumn{3}{|c|}{ Ozone decomposition in catalytic ozonation, $\%$} \\
\hline $\mathrm{p}-\mathrm{CBA}$ & ATZ BTA & $\mathrm{CBZ}$ \\
\hline $95 \%$ & $95 \% \quad 95 \%$ & $>99 \%$ \\
\hline
\end{tabular}

Table 9. Micropollutant removal and ozone decomposition in catalytic ozonation with zeolite ( $\mathrm{C}_{0}$, ozone: $2 \mathrm{mg} / \mathrm{L}, \mathrm{C}_{0}, \mathrm{MP}: 2 \mu \mathrm{M}, \mathrm{pH}: 7$, contact time: $7 \mathrm{~min}$ ).

\begin{tabular}{|c|c|c|}
\hline \multicolumn{3}{|c|}{ ZEOLITE } \\
\hline \multicolumn{3}{|c|}{ Micropollutant Removal, \% } \\
\hline Micropollutant & Adsorption & Catalytic ozonation \\
\hline $\mathrm{p}-\mathrm{CBA}$ & $4 \%$ & $47 \%$ \\
\hline ATZ & $4 \%$ & $67 \%$ \\
\hline BTA & $5 \%$ & $>99 \%$ \\
\hline CBZ & $<2 \%$ & $>99 \%$ \\
\hline \multicolumn{3}{|c|}{ Ozone decomposition in catalytic ozonation, $\%$} \\
\hline $\mathrm{p}-\mathrm{CBA}$ & ATZ BTA & CBZ \\
\hline $92 \%$ & $84 \%>99 \%$ & $92 \%$ \\
\hline
\end{tabular}

Micropollutant removal achieved inside the membrane was determined as $21 \%, 27 \%, 63 \%$ and more than $99 \%$ for p-CBA, atrazine, benzotriazole and carbamazepine, respectively. Micropollutant removal via ozonation for a period of time equal to the catalytic ozonation contact time (7 min) was calculated as $31 \%$ and $57 \%$ for p-CBA and atrazine, respectively, while for benzotriazole and carbamazepine this percentage exceeded $98 \%$.

The influence of $\mathrm{pH}$ value and catalytic ozonation contact time was also examined and the results are shown in Figures 2 and 3, respectively. 


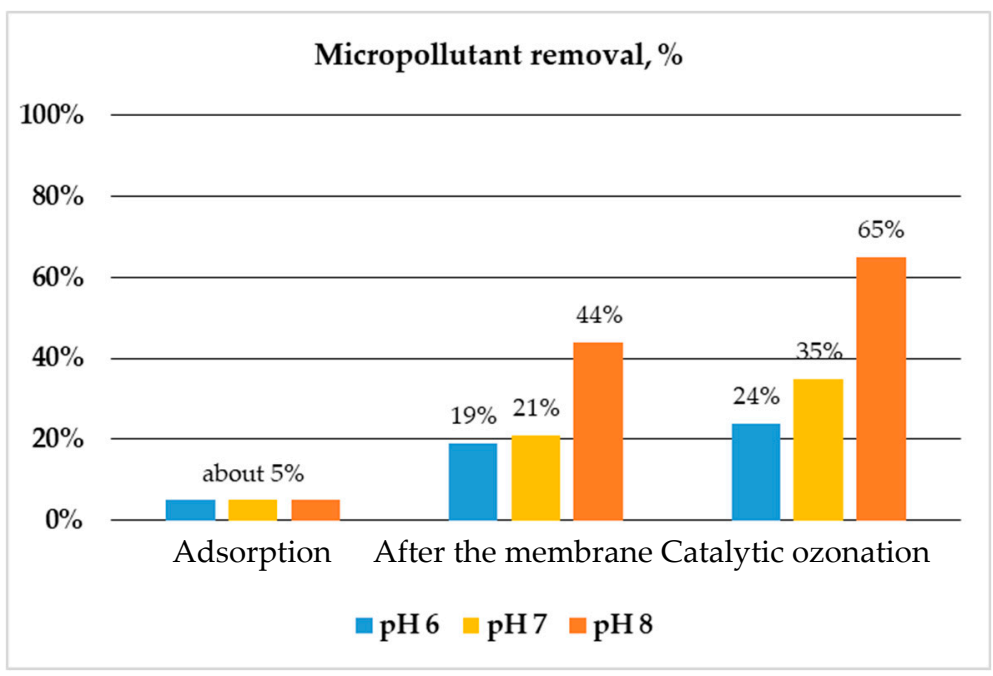

Figure 2. Influence of $\mathrm{pH}$ in catalytic ozonation ( $\mathrm{C}_{0}$, ozone: $2 \mathrm{mg} / \mathrm{L}$, micropollutant (MP): $\mathrm{p}-\mathrm{CBA}, \mathrm{C}_{0}$, $\mathrm{MP}$ : $2 \mu \mathrm{M}$, contact time: $7 \mathrm{~min}$, catalyst: PET).

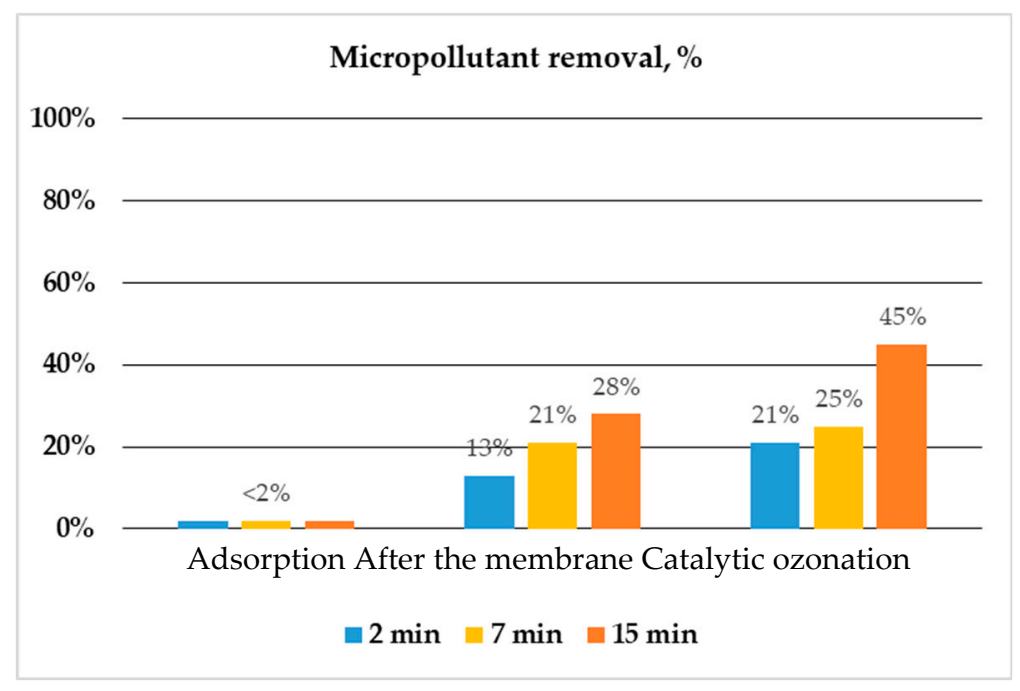

Figure 3. Influence of contact time in catalytic ozonation ( $\mathrm{C}_{0}$, ozone: $2 \mathrm{mg} / \mathrm{L}, \mathrm{MP}$ : p-chlorobenzoic acid (p-CBA), Co, MP: $2 \mu \mathrm{M}, \mathrm{pH}$ 7, catalyst: goethite).

\section{Conclusions}

In the present research work a series of materials were tested as catalysts for the degradation of micropollutants from water in a continuous flow catalytic ozonation system comprising of a hydrophobic membrane and a column filled with granules of the catalyst. Experimental results revealed zeolite as the most effective material in catalytic ozonation achieving complete degradation of benzotriazole (moderately $\mathrm{O}_{3}$-reactive compound) and carbamazepine (easy-reactive compound), $70 \%$ removal of atrazine and about $50 \%$ of p-CBA ( $\mathrm{O}_{3}$-resistant compound) at pH 7. PET also demonstrated a significant performance removing $35 \%$ of p-CBA, $53 \%$ of atrazine and more that $99 \%$ of benzotriazole and carbamazepine. The rest of catalysts tested presented a moderate performance in micropollutant removal with an average of $37 \%$ for atrazine, $29 \%$ for p-CBA, more than $90 \%$ for benzotriazole and complete degradation of carbamazepine. Adsorption capacity of all materials examined did not exceed 5\% suggesting that adsorption had a trivial contribution in micropollutant removal. However, a significant part of the micropollutant degradation took place inside the membrane used for ozone dilution to the aquatic phase and particularly $21 \%, 27 \%$ and $63 \%$ for pCBA, atrazine and benzotriazole, respectively, and total for carbamazepine. Comparison of catalytic with single ozonation demonstrated an increase in efficiency within a range of $10 \%$ to $15 \%$ for zeolite but similar performance, or in the case of atrazine lower, for the rest of materials tested. An increase 
in $\mathrm{pH}$ value significantly improved the performance of the process, multiplying it by more than 2.5 times by $\mathrm{pH}$ rising from 6 to 8 . This can be attributed to the catalysis of ozone decomposition by hydroxyl ions $\mathrm{OH}^{-}$in water over the $\mathrm{pH}$ range 1-8 [19]. Higher contact times also upgraded catalytic ozonation, at least up to the level of $15 \mathrm{~min}$ that was tested.

Author Contributions: All authors have read and agree to the published version of the manuscript. Conceptualization, E.K., A.Z. and M.M.; methodology, E.K. and M.M.; validation, E.K. and M.M.; formal analysis, E.K.; investigation, E.K., C.K. and S.P.; resources, A.Z. and M.M.; data curation, E.K. and S.P.; writingoriginal draft preparation, E.K.; writing-review and editing, A.Z., M.M. and S.P.; visualization, E.K.; supervision, A.Z. and M.M.; project administration, A.Z.; funding acquisition, A.Z. All authors have read and agreed to the published version of the manuscript.

Funding: This research has been co-financed by the European Union and Greek national funds through the Operational Program Competitiveness, Entrepreneurship and Innovation, under the call RESEACH-CREATEINNOVATE (project code: T1EDK-02397).

Conflicts of Interest: The authors declare no conflict of interest

\section{References.}

1. Luo, Y.; Guo, W.; Ngo, H.; Nghiem, L.; Hai, F.; Zhang, J.; Liang, S.; Wang, X. A review on the occurrence of micropollutants in the aquatic environment and their fate and removal during wastewater treatment. Sci Total Environ. 2014, 473, 619-641, doi:10.1016/j.scitotenv.2013.12.065.

2. Margot, J.; Rossi, L.; Barry, D.; Holliger, C. A review of the fate of micropollutants in wastewater treatment plants. WIREs Water 2015, 2, 457-487, doi:10.1002/wat2.1090.

3. Psaltou, S.; Stylianou, S.; Mitrakas, M.; Zouboulis, A. Heterogeneous catalytic ozonation of p-chlorobenzoic acid in aqueous solution by FeMnOOH and PET. Separations 2018, 5, 42, doi:10.3390/separations5030042.

4. Kovalova, L.; Siegrist, H.; von Gunten, U.; Eugster, J.; Hagenbuch, M.; Wittmer, A.; Moser, R.; McArdell, C.S. Elimination of micropollutants during post-treatment of hospital wastewater with powdered activated carbon, ozone and UV. Environ. Sci. Technol. 2013, 47, 7899-7908, doi:10.1021/es400708w.

5. Yangali-Quintanilla, V.; Maeng, S.; Fujioka, T.; Kennedy, M.; Li, Z.; Amy, G. Nanofiltration vs. reverse osmosis for the removal of emerging organic contaminants in water reuse. Desalin. Water Treat. 2011, 34, 50-56, doi:10.5004/dwt.2011.2860.

6. Sahar, E.; David, I.; Gelman, Y.; Chikurel, H.; Aharoni, A.; Messalem, R.; Brenner, A. The use of RO to remove emerging micropollutants following CAS/UF or MBR treatment of municipal wastewater. Desalination 2011, 273, 142-147, doi:10.1016/j.desal.2010.11.004.

7. Radjenovic, J.; Petrovic, J.; Barceló, D. Fate and distribution of pharmaceuticals in wastewater and sewage sludge of the conventional activated sludge (CAS) and advanced membrane bioreactor (MBR) treatment. Water Res. 2009, 43, 831-841, doi:10.1016/j.watres.2008.11.043.

8. Steinle-Darling, E.; Litwiller, E.; Reinhard, M. Effects of sorption on the rejection of trace organic contaminants during nanofiltration. Environ. Sci. Technol. 2010, 44, 2592-2598, doi:10.1021/es902846m.

9. Kovalova, L.; Siegrist, H.; Singer, H.; Wittmer, A.; McArdell, C. Hospital wastewater treatment by membrane bioreactor: Performance and efficiency for organic micropollutant elimination. Environ. Sci. Technol. 2012, 46, 1536-1545, doi:10.1021/es203495d.

10. Sauvé, S.; Desrosiers, M. A review of what is an emerging contaminant. Chem. Cent. J. 2014, 8, 15, doi:10.1186/1752-153X-8-15.

11. Nawrocki, J. Catalytic ozonation in water: Controversies and questions. Discussion paper. Appl. Catal. B Environ. 2013, 142, 465-471, doi:10.1016/j.apcatb.2013.05.061.

12. Guo, Y.; Wang, H.; Wang, B.; Deng, S.; Huang, J.; Yu, G., Wang, Y. Prediction of micropollutant abatement during homogeneous catalytic ozonation by a chemical kinetic model. Water Res., 2018, 142, 383-395, doi:10.1016/j.watres.2018.06.019.

13. Yang, J.; Li, J.; Dong, W.; Ma, J.; Cao, J.; Li, T.; Li, J.; Gu, J.; Liu, P. Study on enhanced degradation of atrazine by ozonation in the presence of hydroxylamine. J. Hazard. Mater. 2016, 316, 110-121, doi:10.1016/j.jhazmat.2016.04.078.

14. Roshani, B.; McMaster, I.; Rezaei, E.; Soltan, J. Catalytic ozonation of benzotriazole over alumina supported transition metal oxide catalysts in water. Sep. Purif. Technol. 2014, 135, 158-164, doi:10.1016/j.seppur.2014.08.011. 
15. Rosal, R.; Rodríguez, A.; Gonzalo, M.S.; García-Calvo, E. Catalytic ozonation of naproxen and carbamazepine on titanium dioxide. Appl. Catal. B Environ. 2008, 84, 48-57, doi:10.1016/j.apcatb.2008.03.003.

16. Lan, B.; Huang, R.; Li, L.; Yan, H.; Liao, G.; Wang, X.; Zhang, Q. Catalytic ozonation of p -chlorobenzoic acid in aqueous solution using Fe-MCM-41 as catalyst. Chem. Eng. J. 2013, 219, 346-354, doi:10.1016/j.cej.2012.12.083.

17. Clesceri, S.L.; Greenberg, E.A.; Trussel, R.R. Inorganic Nonmetals. In Standard Methods for Examination of Water and Wastewater, 17th ed.; American Public Health Association: Washington, DC, USA, 1989; pp. 162-165, ISBN 0-87553-161-X.

18. Kosmulski, M. Surface Charging and Points Zero Charge; CRC: Boca Raton, FL, USA, 2009; p. 145, ISBN 978-1-4200-51889-9.

19. Ershov, B.; Morozov, P. The Kinetics of ozone decomposition in water. Russ. J. Phys. Chem. A 2009, 83, 12951299.

(C) 2020 by the authors. Licensee MDPI, Basel, Switzerland. This article is an open access article distributed under the terms and conditions of the Creative Commons Attribution (CC BY) license (http://creativecommons.org/licenses/by/4.0/). 